\title{
THE STRESS ANALYSIS ON TWO DIFFERENT ADHESIVELY BONDED T-JOINTS VIA 3D NONLINEAR FINITE ELEMENT METHOD
}

\author{
Elanur ÇELEBI KAVDIR ${ }^{1, *}$, Murat Demir AYDIN ${ }^{1}$
}

\begin{abstract}
Adhesively bonded joints are formed in different configurations. T- adhesively bonded joint is one of these configurations and has an important position in industrial applications. The purpose of this study was to numerically study the stress distributions, strength, damage evolution of different T-joints with or without adhesive filling at the curvature of the L-shaped adherends under tensile load via 3D nonlinear finite element method. Here, type-I T-joint is the first model without adhesive filling at the curvature of the L-shaped adherends and type-II T-joint is the second model with adhesive filling at the curvature of the L-shaped adherends. In this study, FM73 and 3M 2214 adhesives and AA2024-T3 aluminum alloy adherends have been used to create two different T-joints numerically. Numerical analysis results have shown that the presence of filler adhesive has a direct influence on joint strength. It has also been observed that $\mathrm{ABCD}$ interface is the most critical region in terms of damage occurrence, while is $\mathrm{AB}$ and $\mathrm{BC}$ lines on the $\mathrm{ABCD}$ interface are the most critical lines. In addition, it was observed upon comparing the stress distributions of lines $\mathrm{AB}$ and $\mathrm{BC}$ that the shear and normal stress values decreased in lines $\mathrm{AB}$ and $\mathrm{BC}$ of the type-II T-joints. Therefore, it can be put forth that the strength of Type-II T-joints is greater in comparison with the strength of type-I T-joints and the use of a type-II T-joints is more suitable for loads which are close to the fracture load of the T-joints.
\end{abstract}

\section{Keywords: T Adhesively Bonded Joints, Finite Element Method}

\section{INTRODUCTION}

Adhesively bonded joints are widely used in important fields such as aerospace, automotive and marine industries by means of developing technology due to their advantages over traditional joining methods such as rivets and bolts. Even though adhesively bonded joints provide significant advantages, it is not easy to determine the stress-strain distributions and joint strength due to the complexity of joint analysis. A number of studies have been carried out on the stress analysis of adhesively bonded joints to ensure the safe use of adhesive joints.

Adhesive joints are formed in different configurations in order to ensure the proper requirements for their use. T joint type is one of these configurations and the analysis of this joint type is more complicated in comparison with the analysis of single and double lap joints. It can be observed as a result of a literature survey that many experimental and numerical studies have been carried out on the analysis of the $T$ joint type. Mechanical properties of T-joints vary depending on such factors as the joint dimensions, length of the overlap and the dimensions of the adherend material. It is very important to investigate the effects of these factors in terms of achieving optimum connection designs [1]. Adams et al set forth the joint variations encountered in practice [2]. Lucas da Silva and Adams investigated the fracture loads in $\mathrm{T}$ joint variations and determined the most effective main parameter in joint strength among these variations [3]. Embedded and non-embedded $\mathrm{T}$ adhesively, joints were experimentally and numerically analyzed during the study carried out by Aydin and Akpinar for investigating the effects of geometric changes on $\mathrm{T}$ joint strength. Numerical analysis via 3D nonlinear finite elements method and experimental studies conducted by subjecting two different $\mathrm{T}$ joint samples to tensile load were found to be a good fit and indicated that the embedded model could carry more load than the nonembedded model. In addition, stress distributions on the adhesive layer were obtained via finite elements method [4]. Abdullah et al. carried out experimental studies for determining the impact of adhesive thickness on tensile strength. The fracture loads of the joints (with adhesive thickness $0.5 \mathrm{~mm}, 1 \mathrm{~mm}, 1.5 \mathrm{~mm}$ and $2 \mathrm{~mm}$ ) subjected to tensile load were determined during this study. It was put forth as a result that the highest strength is achieved with an adhesive layer

This paper was recommended for publication in revised form by Regional Editor Hakan Demir

${ }^{1}$ Department of Mechanical Engineering, Erzurum Technical University, TURKEY

*E-mail address: elanur.celebi@erzurum.edu.tr

Orcid id: 0000-0003-1312-403X

Manuscript Received 28 Feb 2018, Accepted 07 August 2018 
thickness of $1 \mathrm{~mm}$ [5]. Experimental and numerical analyzes of T-joints in different configurations have been performed by Zhan et al [1].

Apalak et al. examined the stress distributions in the adhesive layer via finite element method for a double supported T-joint subject to three different loads. It was set forth as a result of this study that the increase in the support length increases the rigidity of the joint thereby decreasing stresses in the adhesive layer for all loading situations [6].

The strength of adhesively bonded joints varies depending on factors such as joint geometry, material properties and environmental conditions. The effect of these factors on bond strength was investigated experimentally and numerically by many researchers. Izzawati et al numerically investigated the effects of the change in temperature on the stress distribution of T-joints in this work performed via finite element method and compared the changes in temperature at five different temperatures: room temperature, $35^{\circ} \mathrm{C}, 55^{\circ} \mathrm{C}, 75^{\circ} \mathrm{C}$ and $100^{\circ} \mathrm{C}$. It was put forth as a result of this study that the increase in temperature increases the stresses at the joint due to the increase of the plastic deformation ability of the adhesive layer [7].

Bianchi et al., developed a FEM model to investigate the mechanical properties of composite T-joints subjected to tensile loading. Joints were formed with and without pin. Experimental investigation has shown that joints with pin have higher resistance. In addition, FEM was used to verify the experimental results [11]. May and Hesebeck performed experimental analyzes of metallic T-adhesively bonded joints formed using two different adhesives. T-joints were loaded in three different directions and at three different loading velocities since different fracture mechanisms occur at different loading directions $(0.5 \mathrm{~mm} / \mathrm{s}, 50 \mathrm{~mm} / \mathrm{s}$ and $5000 \mathrm{~mm} / \mathrm{s})$. Statistically significant differences between the two models were reported as a result of the study due to the use of different adhesives [12].

Carneiro and Campilho carried out experimental and numerical analyses on the behavior of T-joints under peel loads. Two different adhesives with different ductility were used in the experimental study and the joint strength was evaluated with different thickness values for the L-shaped adherends. Joint strength, damage evolution, stress distributions and the impact of presence of filler adhesive (joints with or without adhesive filling at the curvature of the L-shaped adherends) were studied during a numerical study performed using cohesive zone models (CZM). As a result, the experimental tests validated the numerical results and it was observed that the type of adhesive and the presence of filler adhesive are important parameters for joint strength [13].

Azam et al. studied the effects of various ply-layup orientations on bending stiffness of a composite T-joint. In this study, the in-plane and out-of-plane stresses of the composite T-joint were investigated under three-point bending conditions. Azam et al. developed a three-dimensional finite element model of the composite T-joint and showed that the finite element model is compatible with experimental results. The authors reported at the end of the study that bending stiffness is influenced by plies and that symmetric layups reduce bending stiffness. It was also observed that out of plane effects were appreciable and thus the overall magnitudes of the out of plane shear stresses were not as important as inplane stresses [14].

Statistical experimental design techniques were used during the study by Sutherland et al. for investigating the strength of T-Joints formed with different adhesives and surface preparations via a large test program. Sutherland et al. carried out an analysis of variance providing an extremely good fit to the experimental data to investigate the effects of varieties. It has been reported as a result of the study that 'the effect of each parameter varied considerably between the different levels of the other parameters. It has also been indicated that interaction plots are very important due to the advantages of interpreting the results and understanding and presenting the complicated relationships observed in the data [15].

Khosravani and Weinberg carried out studies on the numerical and experimental investigations of composite honeycomb sandwich T-joints. The effects of loading and ageing on adhesively bonded joints were investigated in the study. Khosravani and Weinberg performed quasi-static tension experiments with original T-joints and with two sets of artificially aged specimen in the experimental study. As a result of the failure behavior of the original and the aged specimens are determined to provide for analysis of T-joints and the results are verified with three-dimensional finite element analyses using a cohesive zone element method [16].

T-joints made from carbon/epoxy composites have been used in aeronautical structures, however delamination is a major issue in these structures. Bigaud et al. carried out an experimental study on this subject. The objective of the study was to increase the transverse strength through-the-thickness reinforcements for laminate composites. Bigaud et al. 
used carbon/epoxy T-joints reinforced transversally by one side stitching (OSS) and molded on Resin Transfer Molding (RTM). Analysis of strain field of unstitched T-joints was performed by DIC (Digital Image Correlation). Additionally, the stitched samples were analyzed during the tests via microscopy and Scanning Electron Microscopy. Consequently, it has been reported that the stitch pattern affects the strain fields asymmetrically and increases ultimate strength (25\%) [17].

Li et al. conducted an experimental and numerical study to investigate the effect of cyclic-temperature environment on adhesively bonded T-joints. Steel and aluminum T- joints were used in the experimental study to illustrate the influence of cyclic temperature on the fracture load of T-joints. ABAQUS finite element software was used for numerical analysis by a cohesive zone model (CZM) to investigate the impact of temperature variation on strength of Tjoints. It has been reported as a result of the experimental study that the ultimate load of the T-joints changed with effects of long-term cyclic-temperature and decreased with the increase of temperature cycles. It has also been shown that the experimental and numerical results are compatible [18].

Finite element method is used effectively in the analysis of many fields, as in the analysis of bonding joints. In a study by Şenalp; the effects of geometry and load perturbation on the buckling behavior of multilayer pressure vessel heads were investigated by non-linear finite element method via ANSYS Workbench program. In the study, two-layer (steel - aluminum and titanium - aluminum configurations) and three-layer (copper - steel - copper) torispheric heads are considered. As a result of this study; it was concluded that in steel-aluminum configurations for two-layer structures, geometric perturbation is more critical than load perturbation, and geometric and load perturbation cause the structure to buckling at a lower pressure value [19].

It was decided to carry out this study which is thought to make a contribution to this field as a result of the conclusion reached at the end of the literature survey since it was concluded that studies on stress analysis of $\mathrm{T}$ bonding joints are inadequate. It was observed upon conducting a literature survey that the middle region of the joints, created in studies related to the $\mathrm{T}$ joint, is empty (as type-I). Therefore, full and empty models were analyzed and compared in terms of stresses based on the idea of filling the middle region with adhesive (type-II) to improve the mechanical properties of the T-joints.

In this study, the stresses on the double-supported T-joints, which are empty and full the back area of the $4.1 \mathrm{~mm}$ radius which is behind the support were analyzed numerically. These different $T$ joints with adhesives (FM®73 and $3 \mathrm{M}$ 2214) and adherent materials (AA2024-T3) were analyzed via 3-dimensional nonlinear finite elements method considering a nonlinear material behavior and geometric nonlinearity after which the obtained results were compared.

\section{NUMERICAL MODELING}

\section{Material properties}

In this study, (AA2024-T3) aluminum alloy adherents and FM®73 - 3M 2214 structural adhesives were used. Mechanical properties and stress-strain curves of these materials have been shown in Table 1 [8].

Table 1. Mechanical properties of adhesives and adherend materials [4, 8]
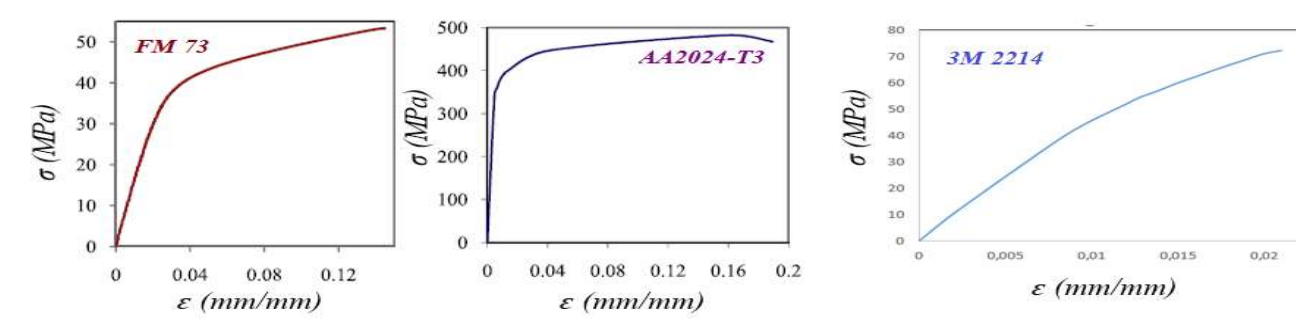

\begin{tabular}{cccc} 
Properties & AA2024-T3 & 3M 2214 & FM $^{\circledR}$ 73 \\
\hline$E(\mathrm{MPa})$ & 71875 & 5113.44 & 1551.27 \\
$V$ & 0.33 & 0.35 & 0.35 \\
\hline
\end{tabular}

$E$ : Elasticity module, $v$ : Poisson ratio 


\section{Geometric Parameters of T-Joints Used in Numerical Analysis}

Two different T-joints were modeled for numerical analysis in this study. Dimensions of these joints are given in Figure 1. The back area of the $4.1 \mathrm{~mm}$ radius behind the supports (L-shaped adherends) is empty in Type-I and the back area of the $4.1 \mathrm{~mm}$ radius behind the supports is filled in Type-II.

(a) TYPE-I

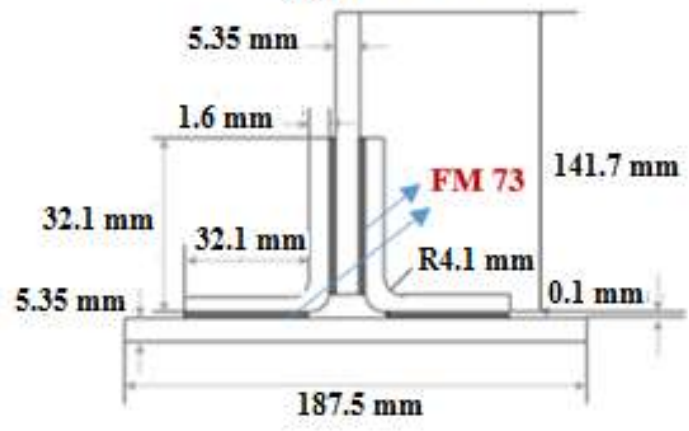

(b) TYPE-II

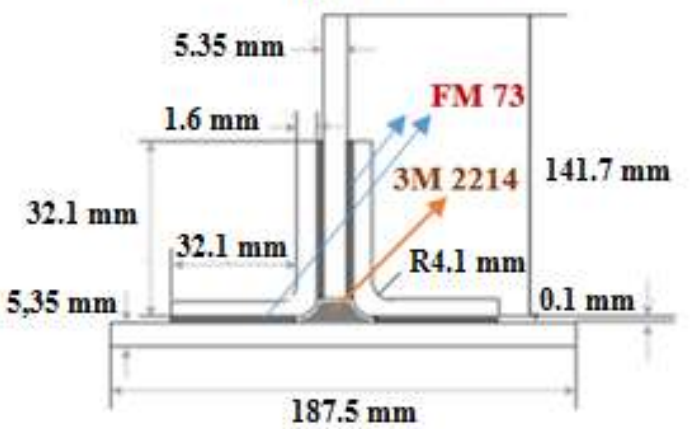

Figure 1. Dimensions of T-joins in numerical analysis: (a) (Type I), (b) (Type II) (width $25 \mathrm{~mm}$ for two model)

\section{Numerical analysis}

During the analysis of elasto-plastic finite element of two different $T$-joints with dimensions as specified in Figure 1, the joints were modeled in 3D via ANSYS Workbench 16.0 package program. $T$-joints were modeled using Solid 186 elements with 3 degrees of freedom and 20 node points and in the contact area, Conta 174 and Targe 170 elements with bonded contact mode.

Since, the finite element method yields approximate solutions, the model can be improved to increase the precision of the result. One of the most important factors affecting this precision is the mesh status. More accurate results achieved by improving the mesh status to increase the polynomial grade of the used elements or number of elements. In this study, the model was optimized by forming a denser mesh structure to use more elements in regions where stress variations may be high. The same mesh structure was created in type-I and type-II $T$ - joints in terms of a correct comparison of the stresses that occur at the same load and location of joints. Figure 2 shows the mesh structures of the $T$ joints and the load and boundary conditions applied to these joints.

(a)

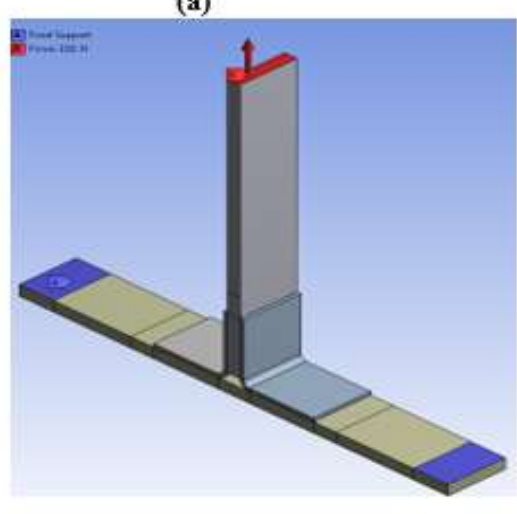

(b)

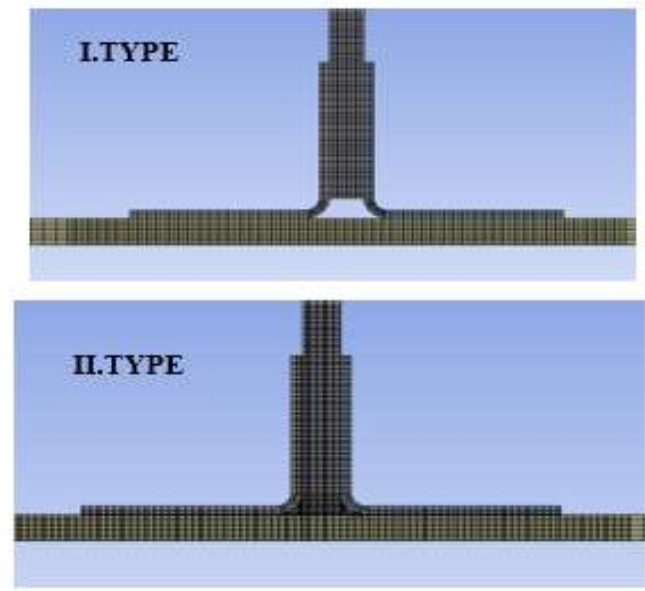

Figure 2. T-joints used in numerical analysis are (a) load and boundary conditions, (b) mesh structures 
Journal of Thermal Engineering, Research Article, Vol. 6, No. 2, Special Issue 11, pp. 170-179, March, 2020

\section{RESULTS AND DISCUSSION}

Numerical stress analysis of $T$-joints was performed at $3000 \mathrm{~N}$ load during this study. The difference, between the stress values of $\mathrm{T}$ joints was investigated numerically at the same load.

Table 2. Load values, applied to T-joints

\begin{tabular}{|c|c|}
\hline Type-I T-joint & Type-II T-joint \\
\hline $3000 \mathrm{~N}$ & $3000 \mathrm{~N}$ \\
\hline
\end{tabular}

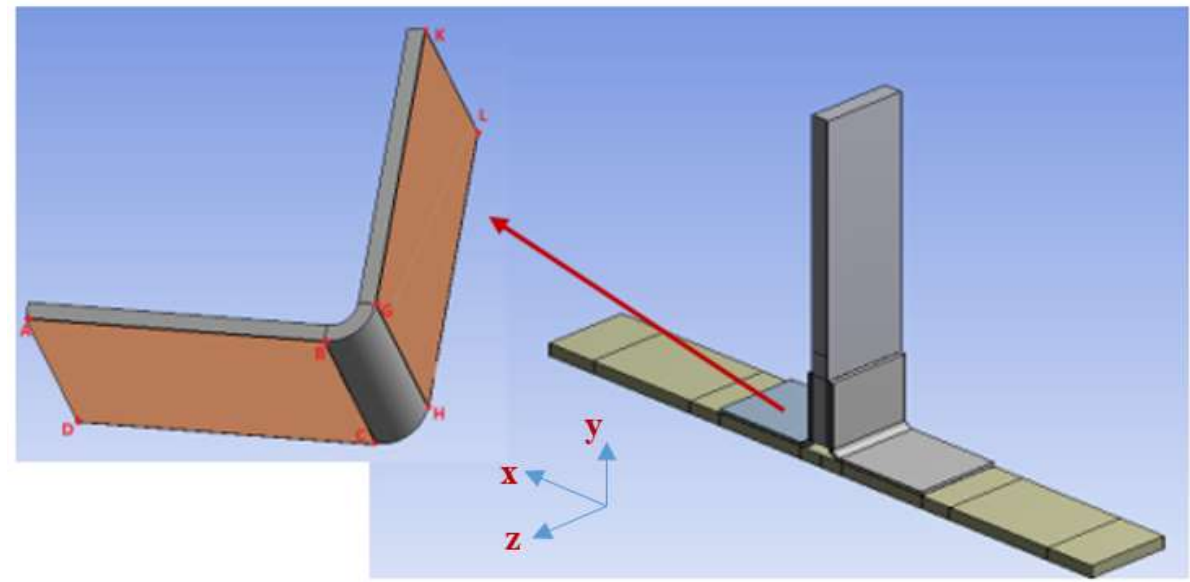

Figure 3. Critical damage surfaces at T-joints

(a)

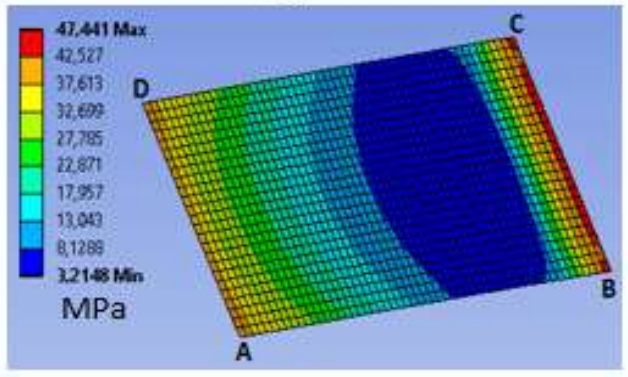

(c)

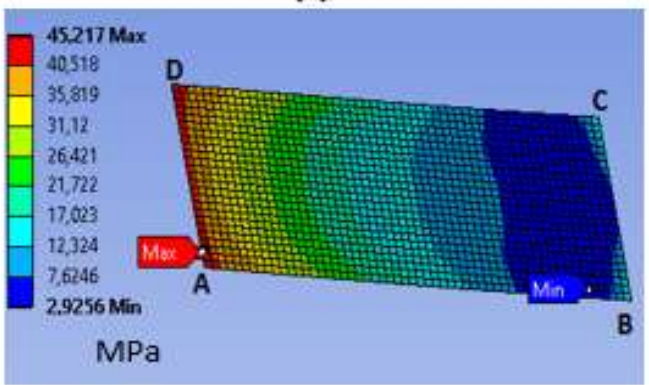

(b)

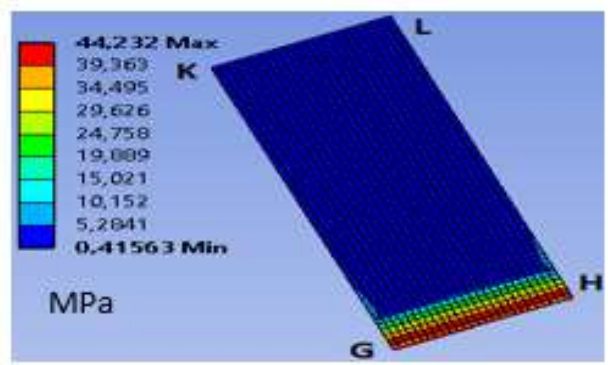

(d)

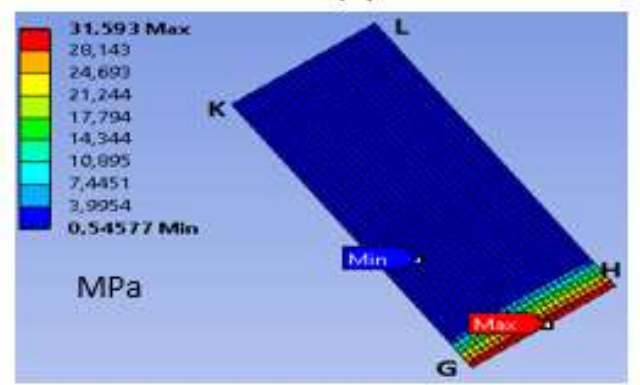

Figure 4. Von-Misses stress distributions in adhesive layers; (a) the ABCD surface of type-I T-joint, (b) the GHKL surface of type-I T-joint; (c) the ABCD surface of the type-II T-joint, (d) the GHKL surface of type-II T-joint 
Firstly, the areas which are critical for damage must be identified for analysis. It has been reported in literature that the critical regions which have significant effect at the onset of damage are the adhesive and adherent material interfaces (ABCD and GHKL) as can be seen from Figure $3[6,9,10]$.

It was observed as a result of the numerical analyzes carried out in this study that the von-Misses stress value on the $\mathrm{ABCD}$ surface is higher in comparison with that on the GHKL surface (Figure 4). In addition, the stresses on $\mathrm{AB}$ and $\mathrm{BC}$ lines have been evaluated and compared due to their high stress values. Figure 3 shows the critical damage surfaces on T-joints whereas Figure 4 shows the Von-Mises stress distribution for the ABCD and GHKL surfaces.

(a)

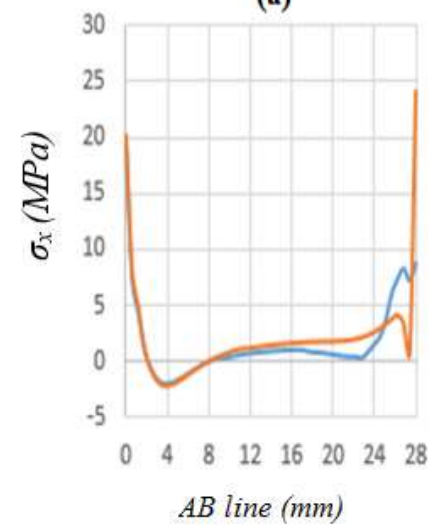

(d)

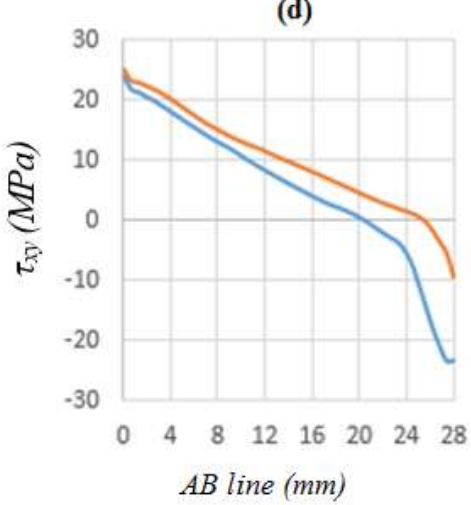

(b)

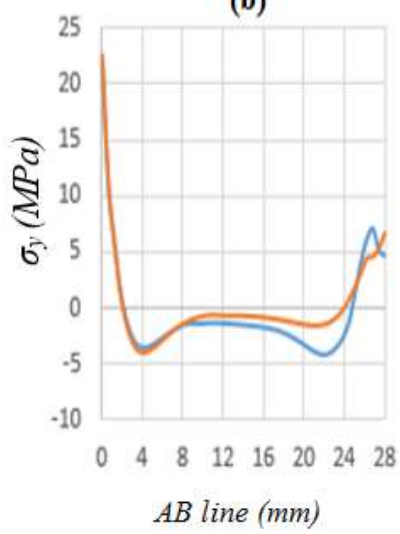

(e)

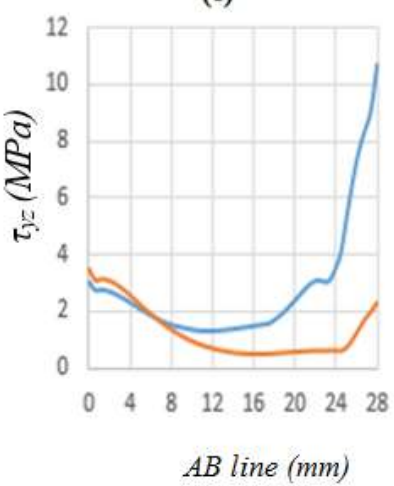

(c)

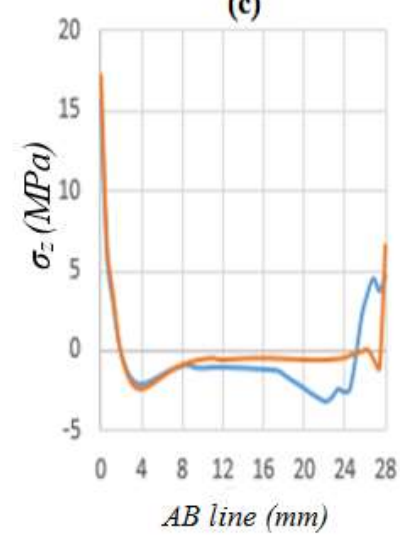

(f)

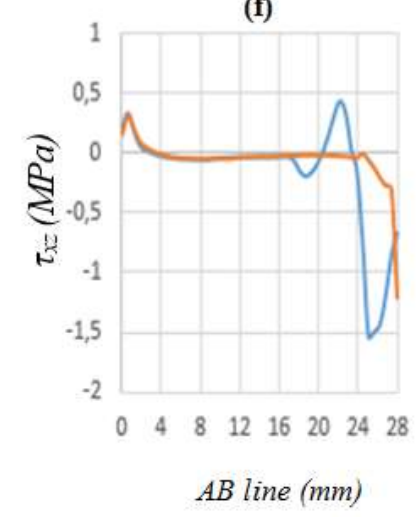

Figure 5. Stresses in the AB line of the ABCD surface of the adhesive layer; (a) $\sigma_{x}$, (b) $\sigma_{y}$, (c) $\sigma_{z}$, (d) $\tau_{x y}$, (e) $\tau_{y z}$, (f) $\tau_{\mathrm{xz}}$ 
(a)

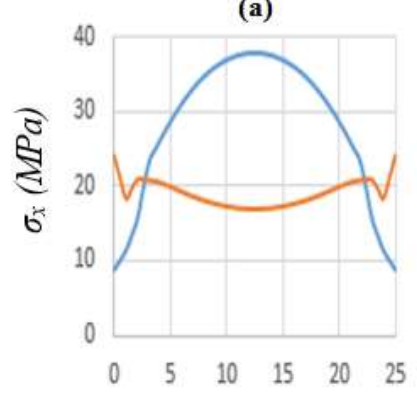

(d)

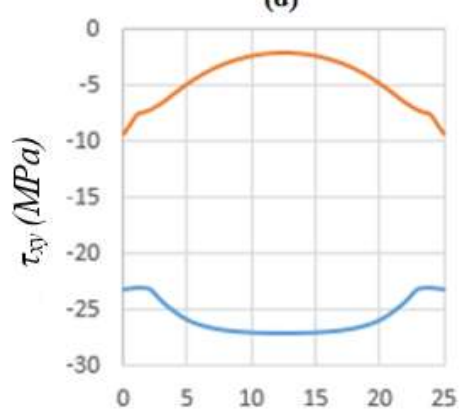

(b)

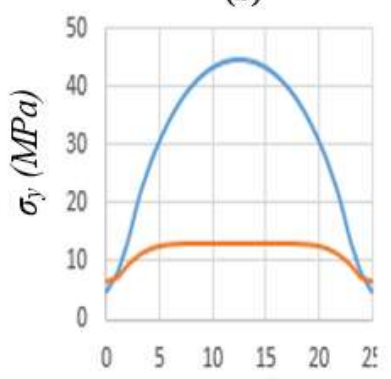

(e)

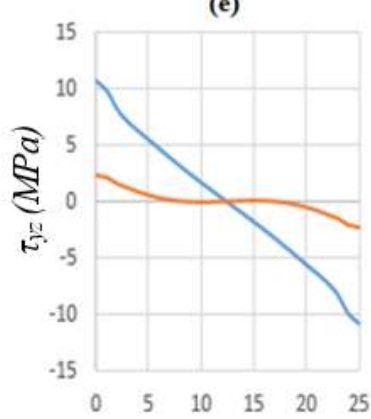

(c)

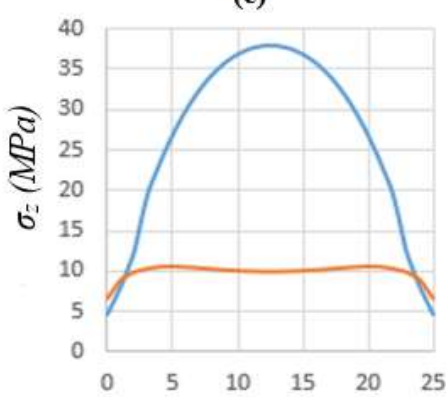

(f)

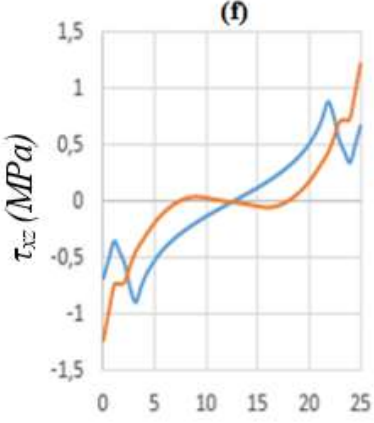

Figure 6. Stresses in the $\mathrm{BC}$ line of the ABCD surface of the adhesive layer; (a) $\sigma_{\mathrm{x}},(\mathrm{b}) \sigma_{\mathrm{y}}$, (c) $\sigma_{\mathrm{z}}$, (d) $\tau_{\mathrm{xy}}$, (e) $\tau_{\mathrm{yz}}$, (f) $\tau_{\mathrm{xz}}(\mathrm{BC}$ line $25 \mathrm{~mm})$

The stress distributions and values in the $\mathrm{AB}$ line of both models have been shown in Figure 5. When the normal stresses are compared, it can be seen that the stress values in the $\mathrm{AB}$ line of both models are very close to each other and that the stress distributions are similar. Additionally, it is also observed that normal stress values are higher than those for type-I joint at the ends of the AB line of the type-II joint (filled model). It can clearly be seen when the shear stress values of the $\mathrm{AB}$ line of both models are compared that the $\tau_{\mathrm{xz}}$ shear stress is at a negligible level for both models. Moreover, it can also be observed that the difference between the shear stresses of the two models is highest at point $\mathrm{B}$ as in the case of normal stress components and there is an increase in the absolute values of shear stresses in type-I.

Figure 6 shows the stress distributions in the $\mathrm{BC}$ line of both models. It can be observed for both models that normal stress values are at a minimum level at the middle of the $\mathrm{BC}$ line and that normal stress values are maximum at the ends of the joints (except for, the normal stress in the $\mathrm{x}$ direction of the type II joint - figure 6a). It can be seen upon comparing type-I and type -II models that the difference between the two models is high. The normal stress values at points $\mathrm{B}$ and $\mathrm{C}$ are higher in type-II model in comparison with the normal stress values at points $\mathrm{B}$ and $\mathrm{C}$ points in type I, whereas the maximum normal stress values in type-I joint are much higher in comparison with those of the other joints. Consequently, it can be said that the strength values of type-II may be higher because type-II joint has a more homogeneous stress distribution and lower stress values are observed at all points throughout BC line in Type-II joint except at points B and C. Additionally, it can clearly be observed upon comparing the shear stress values for the $\mathrm{BC}$ line of both models that the $\tau_{\mathrm{xz}}$ shear stress values are negligible for both models. Moreover, it can also be seen that the difference between the shear stress values for the two models is highest at the middle of the $\mathrm{BC}$ line for xy component of shear stress and there is an increase in the absolute values of the shear stresses in type-I for all components of shear stress. 

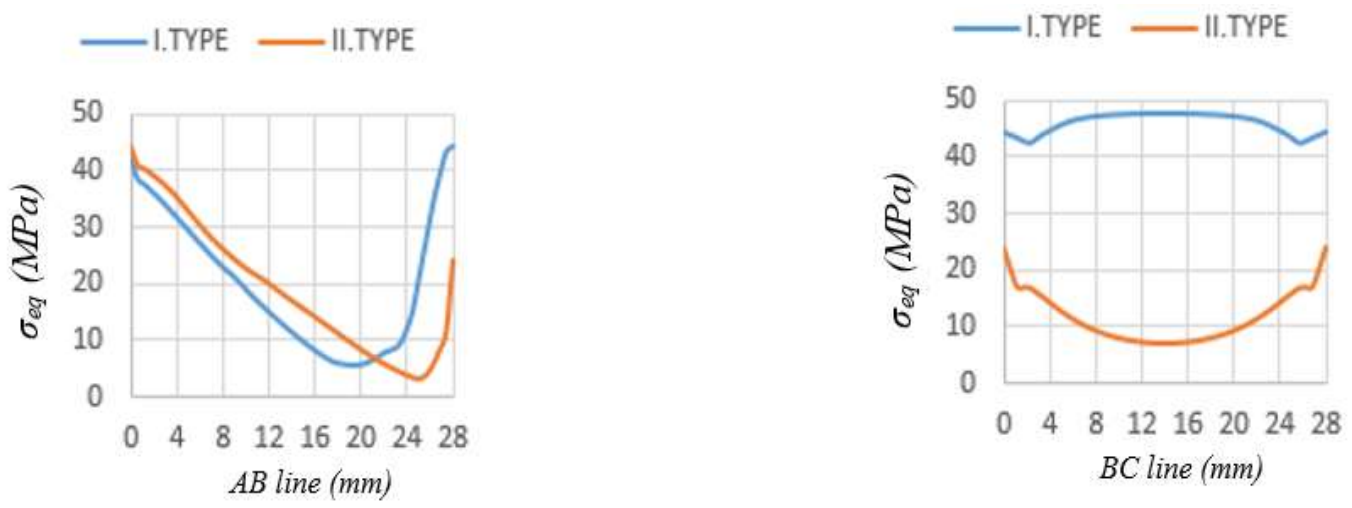

Figure 7. Von-Mises stress distributions in the $\mathrm{AB}$ and $\mathrm{BC}$ lines of the adhesive layer; (a) $\mathrm{AB}$ line, (b) $\mathrm{BC}$ line

It can be observed when the total effect of these 6 stress components on the $\mathrm{AB}$ line is considered that less equivalent stress values are observed in type-II model especially at point B (Figure 7.a). Therefore, it can be said that type-II joint is more durable.

Likewise, it can be observed when the total effect of these 6 stress components on the $\mathrm{BC}$ line is considered that type-II joint has lower stress values at all points of the curve and thus it can be said that type-II joint is more durable (Figure 7.b).

(a)

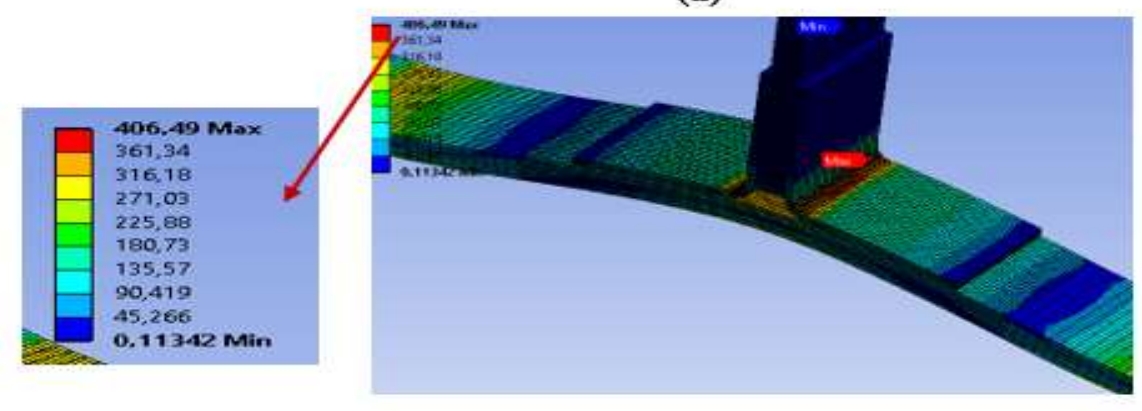

(b)

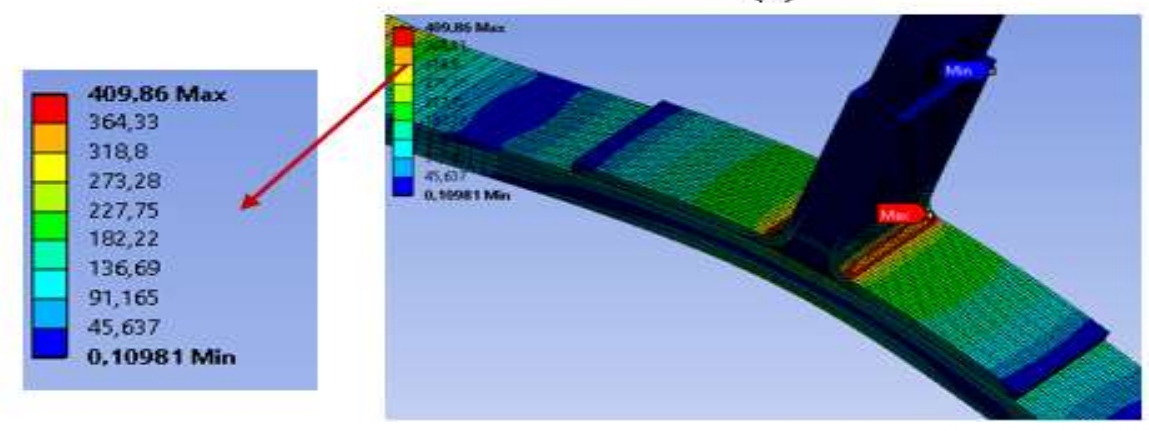

Figure 8. Von - Mises stress distributions in adhesively bonded T joints; (a) Type-I, (b) Type-II

\section{CONCLUSION}

- Type-I joint which has an optimization of weight reduction and is available in literature and type-II joint were compared in this study with regard to normal and shear stresses. Accordingly, it can be said that type-II joint is 
safer than type-I. It can also be said that the use of a type-I joint is not a suitable optimization for loads that are close to the fracture load of the $T$-joints.

- The stresses were compared in the $\mathrm{AB}$ and $\mathrm{BC}$ lines on the $\mathrm{ABCD}$ regions which are critical in terms of the damage initiation of the $\mathrm{T}$-joints. According to this comparison, it can be said that the stresses in the $\mathrm{BC}$ line depend more on the full - empty condition of the model and the values of the normal stress components decrease considerably in type-II joint due to the increased rigidity when the model was filled.

- Peel stress $\left(\sigma_{y}\right)$ has a significant impact on joint strength in T joints. When peel stresses $\left(\sigma_{y}\right)$ were compared, maximum peel stress $\left(\sigma_{y}\right)$ of type-I was observed as $44.463 \mathrm{MPa}$, while maximum peel stress $\left(\sigma_{y}\right)$ of type-II was $13.167 \mathrm{MPa}$. It was seen that this value in type -II model decreased about $71 \%$. In addition, excess peel stress was transferred to the inner regions of the adhesive layer in the type-II joint i.e. a more homogeneous stress distribution was obtained at this joint. Therefore, it can be said that there is an increase in the joint strength of the type II model.

- It was observed upon comparing the shear stresses in $\mathrm{AB}$ and $\mathrm{BC}$ lines that, $\tau_{\mathrm{xz}}$ values were negligible for both models. The values of the other shear stress components decreased in both lines of the type-II model. Thus, typeII model can carry higher loads. Additionally, the difference between the shear stresses of both models was found to be greater in the $\mathrm{BC}$ line as well as for normal stress values.

\section{ACKNOWLEDGEMENT}

This study was financially supported by Erzurum Technical University-through Project no. 2017-9.

\section{REFERENCES}

[1] Zhan X, Gu C, Wu H, Liu H, Chen J, Chen J, Wei Y. Experimental and numerical analysis on the strength of 2060 Al-Li alloy adhesively bonded T joints. International Journal of Adhesion and Adhesives 2016; 65, 79-87. https://doi.org/10.1016/j.ijadhadh.2015.11.010.

[2] Adams RD, Comyn J, Wake WC. Structural adhesive joints in engineering. Springer Science \& Business Media, 1997.

[3] Da Silva LF, Adams RD. The strength of adhesively bonded T-joints. International journal of adhesion and adhesives 2002; 22(4), 311-315. https://doi.org/10.1016/S0143-7496(02)00009-X.

[4] Aydin MD, Akpinar S. The strength of the adhesively bonded T-joints with embedded supports. International Journal of Adhesion and Adhesives 2014; 50, 142-150. https://doi.org/10.1016/j.ijadhadh.2013.12.028.

[5] Abdullah AR, Afendi M, Majid MA. Effect of adhesive thickness on adhesively bonded T-joint. In IOP Conference Series: Materials Science and Engineering (Vol. 50, No. 1, p. 012063). IOP Publishing, 2013.

[6] Apalak ZG, Apalak MK, Davies R. Analysis and design of tee joints with double support. International journal of adhesion and adhesives 1996; 16(3), 187-214. https://doi.org/10.1016/0143-7496(96)87013-8.

[7] Izzawati B, Afendi M, Nurhashima S, Nor A, Abdullah AR, Daud R. Evaluation of Adhesive T-joint Using Finite Element Analysis. Applied Mechanics \& Materials 2015; 786.

[8] Aydin MD. 3-D nonlinear stress analysis on adhesively bonded single lap composite joints with different ply stacking sequences. The Journal of Adhesion 2008; 84(1), 15-36. https://doi.org/10.1080/00218460801888359.

[9] Kumar S, Pandey PC. Behaviour of bi-adhesive joints. Journal of Adhesion Science and Technology 2010; 24(7), 1251-1281. https://doi.org/10.1163/016942409X12561252291982.

[10] Khalili SMR, Ghaznavi A. Numerical analysis of adhesively bonded T-joints with structural sandwiches and study of design parameters. International Journal of Adhesion and Adhesives 2011; 31(5), 347-356. https://doi.org/10.1016/j.ijadhadh.2010.12.005.

[11] Bianchi F, Koh TM, Zhang X, Partridge IK, Mouritz AP. Finite element modelling of z-pinned composite Tjoints. Composites Science and Technology 2012; 73, 48-56. https://doi.org/10.1016/j.compscitech.2012.09.008.

[12] May M, Hesebeck O. Failure of adhesively bonded metallic T-joints subjected to quasi-static and crash loading. Engineering Failure Analysis 2015; 56, 454-463. https://doi.org/10.1016/j.engfailanal.2014.12.007.

[13] Carneiro MAS, Campilho RDSG. Analysis of adhesively-bonded T-joints by experimentation and cohesive zone models. Journal of adhesion science and Technology 2017; 31(18), 1998-2014. https://doi.org/10.1080/01694243.2017.1291320. 
[14] Azam A, Mubashar A, Ashcroft IA, Uddin E, Jaffery SHI. A numerical study of the effect of ply-layup on the strength and stiffness of a composite T-joint under three point bending. Journal of adhesion science and Technology 2017; 31(19-20), 2124-2138. https://doi.org/10.1080/01694243.2017.1278818.

[15] Sutherland LS, Amado C, Soares CG. Statistical experimental design techniques to investigate the strength of adhesively bonded T-joints. Composite Structures 2017; 159, 445-454. https://doi.org/10.1016/j.compstruct.2016.09.076.

[16] Khosravani MR, Weinberg K. Characterization of sandwich composite T-joints under different ageing conditions. Composite Structures 2018; 197, 80-88. https://doi.org/10.1016/j.compstruct.2018.05.043.

[17] Bigaud J, Aboura Z, Martins AT, Verger S. Analysis of the mechanical behavior of composite T-joints reinforced by one side stitching. Composite Structures 2018; 184, 249-255. https://doi.org/10.1016/j.compstruct.2017.06.041.

[18] Li W, Pang B, Han X, Tang L, Zhao K, Hu P. Predicting the strength of adhesively bonded T-joints under cyclic temperature using a cohesive zone model. The Journal of Adhesion 2016; 92(11), 892-907. https://doi.org/10.1080/00218464.2015.1055354.

[19] Şenalp Z. Investigation of the Effects of Geometric and Load Perturbation to Buckling in Multilayered Torispherical Pressure Vessel Heads. Journal of Thermal Engineering 2015; 1(6), 203-209. 